stories: the difficulties are clearly nationwide, as a recentlypublished survey on social service departments has shown. ${ }^{4}$ Certainly the R.B. agreed with this diagnosis and it called unanimously for an inquiry "into the working of the Local Authority Social Services Act 1970."

The two major craft con:nittees split Thursday between them and ploughed much familiar ground. Rejecting once again a subconsultant grade, the Representative Body also deplored substandard hospital accommodation and unanimously supported the juniors in their prolonged fight for special risks insurance-this despite an intervention from Mr. Walpole Lewin, who reported that Sir Keith Joseph had just promised him a Government offer in a week. A brisk debate on a proposal to abolish the secrecy of distinction awards for consultants ended in a rebuff for the platform, with the policy-changing motion being approved by the necessary two-thirds majority. On general practice the debate on N.H.S. contraception took up much of the afternoon and the result reinforced the L.M.C. Conference decisions, ${ }^{5}$ with the meeting in no doubt that N.H.S. family doctors should have a separate contract for contraceptive services and should not prescribe devices when no "medical supervision" of the user's health is called for.

Inevitably, medicopolitics dominated the week, and the Chairman of the Representative Body, Dr. J. S. Noble, along with his deputy Dr. A. A. Clark, merited the A.R.M.'s thanks for their firm, courteous conduct of the debates. But other subjects, too, had a good run, with lively discussions on car seat belts - the R.B. wanted their use made compulsory-prescribing habits, smallpox vaccination, dangerous drugs legislation, and population problems. Dr. L. Pierre Ribet, the Folkestone and Dover Division's Chairman, argued persuasively in favour of an emergency dental service in the N.H.S. and the meeting overwhelmingly supported him. A notable feature throughout the meeting was the constructive part played by the juniors.

With visits to France, Glyndebourne, Canterbury, and Dungeness nuclear power station the social side of the week matched the exceptional sunshine. The excellent programme was the culmination of many months planning by Dr. Ribet and his colleagues on the local organizing committees: Mr. D. V. Evans, President, Kent Branch; Dr. Brian Lewis, Honorary General Secretary; and Dr. Guy Whitaker, Honorary Treasurer-ably complemented by the Lad:es Committee. The debates on the constitution showed that whatever the shape of the B.M.A. at the centre, divisional activity is the Association's life blood. Certainly, in their contributions to the meeting, both inside the Leas Cliff Hall and outside it, the Representative Body's hosts showed their vitality.

1 British Medical fournal Supplement, 1972, 4, 55. 2 British Medical fournal Supplement, 1972, 2, 45.

British Medical fournal Supplement, 1972, 3, 31.

4 British Medical Fournal Supplement, 1973, 2, 51

5 British Medical fournal Supplement, 1973, 2, 61.

\section{Better Results in Childhood Acute Leukaemia}

In 1965 a leading article in these columns stated ${ }^{1}$ that, with the use of the five antileukaemic drugs then available (steroids, vincristine, methotrexate, 6-mercaptopurine, and cyclophosphamide) plus supportive measures, $50 \%$ of those treated in many centres survived well over 12 months and
$10 \%$ for over two years. This was contrasted with the prechemotherapeutic era, when half the children with this disease died within two to four months and nearly all within a year. ${ }^{2}$

The considerable advances that have been made since 1965 are shown by the long-term results obtained by $D$. Pinkel's group at Memphis, where over $50 \%$ of the patients on their 1968 schedule have shown no recurrence of leukaemia at four years from diagnosis. ${ }^{3}$ Projection of the curves for duration of remission in their patients suggests that the five-year results may also be in the region of $50 \%$. Rather similar results have been obtained elsewhere. ${ }^{4-7}$ Indeed patients with acute lymphoblastic leukaemia who survive four years without a relapse seem to have as good as a $70 \%$ chance of normal health. 8

A key component of the treatment given by these groups has been the administration of cranial radiotherapy together with either spinal irradiation or a course of intrathecal methotrexate. This prophylactic therapy to the central nervous system is administered in the early stage of remission with the object of destroying the small numbers of leukaemic cells present which are the "seeds" of future meningeal leukaemia. It has reduced the incidence of this complication from $55 \%$ to as low as $5 \%$ among patients with their bone marrow still in the initial remission and constitutes a major advance in long-term management.

Longer remissions are obtained at the cost of immunosuppression caused by the antileukaemic drugs. This accounts for an increased incidence of serious and sometimes fatal infections with varicella and measles as well as with opportunist organisms such as Pneumocystis carinii, henpesvirus, cytomegalovirus, and fungi.9 But halving the dose of the antileukaemic drugs results in grossly inferior duration of remission. Immunological function (cellular as well as humoral) rapidly recovers, however, after stopping the chemotherapy. ${ }^{10}$ It has therefore become a matter a great importance to determine the optimum duration of this type of intensive multi-drug continuous therapy. Pinkel's results suggests that $2 \frac{1}{2}$ to 3 years is adequate. Other clinical trials are in progress to throw more light on this point. Though infection is a hazard, children in remission on continuous chemotherapy return to a normal and full life at home and can attend school, the treatment being given on an outpatient basis.

Two categories of acute leukaemia in childhood have a distinctly less favourable chance of long-term control. These include, firstly, the non-lymphoblastic forms such as myeloblastic, ${ }^{11}$ myelomonocytic, monocytic, ${ }^{12}$ and erythroleukaemia; and, secondly, those cases of lymphoblastic leukaemia presenting with gross splenomegaly, ${ }^{13}$ a rapid clinical onset, ${ }^{14}$ thrombocytopenia and a white cell count of over 20,000/ $\mu 1,1214$ and with a low proportion of the leukaemic blast cells in the marrow showing a positive reaction to the periodic-acid-Schiff stain. ${ }^{15}$ Infants, children over about 10 years, and black children generally do less well than others. Overtly myeloblastic leukaemia should be treated with different drugs (cytosine arabinoside, thioguanine, daunorubicin), and it is possible that lymphoblastic cases with the features noted above would do better on a modified drug schedule.

The extended duration of freedom from recurrence now being achieved in the lymphoblastic form of childhood leukaemia raises the question whether some of these patients are cured. Many patients have remained in remission off chemo- 
therapy for several years. ${ }^{4} 16 \mathrm{~J}$. H. Burchenal, ${ }^{17}$ from a worldwide survey of long-term survivors in acute leukaemia, found that $50 \%$ of those who had survived five years went on to survive 15 years, generally being off all chemotherapy for the latter part of this time, none relapsing after eight years of continuous remission. If this finding can be applied to more recent series, in which 40 to $50 \%$ of patients are expected to reach five years without recurrence, then 20 to $25 \%$ should reach 15 years, which would surely indicate cure.

1 British Medical fournal, 1965, 1, 1328.

2 Tivey, H., Annals of the New York Academy of Sciences, 1954, 60, 322.

3 Lancet, 1972, 2, 910.

4 Holland, J. F., and Glidewell, O., Cancer, 1972, 30, 1480.

s Sinks, L. F., Archives of Disease in Childhood, 1972, 47, 811.

M.R.C. Leukaemia Committee and Working Party on Leukaemia in Childhood, British Medical fournal, 1973, 2, 381.

7 Campbell, A.C., et al., British Medical fournal, 1973, 2, 385.

${ }^{8}$ Till, M. M., Hardisty, R. M., and Pike, M. C., Lancet, 1973, 1, 534.

'Simone, J. V., Holland, E., and Johnson, W., Blood, 1972, 39, 759.

10 Borella, L., Green, A., and Webster, R. G., Blood, 1972, 40, 42.

11 Henderson, E. S., Annals of Internal Medicine, 1968, 69, 628.

12 Zuelzer, W. W., Blood, 1964, 24, 477.

13 Hardisty, R. M., and Till, M. M., Archives of Disease in Childhood, 1968, 43, 107.

14 Acute Leukaemia Group B., Blood, 1963, 21, 699.

15 Acute Leukaemia Group B., Blood, 1963, 21, 699.

16 Pinkel, D., Fournal of the American Medical Association, 1971, 216, 648.

17 Burchenai, J. H., Cancer, 1968, 21, 595.

\section{Disinfecting Ventilators}

For some years there has been concern over the danger of cross-infection from anaesthetic equipment and mechanical ventilators, and there is evidence that this is a real problem, though not an easy one to quantitate. ${ }^{1}$ Apart from the obvious risk that the inside of the machine and the circuit to the patient may become contaminated and so infect subsequent patients, the expired air may carry micro-organisms into the room. The outside of the ventilator may also become a source of infection, as may any other piece of operating-room furniture.

The risk from external contamination of the apparatus is the easiest to deal with, as domestic cleaning or wiping with a liquid disinfectant should probably suffice. The circuit to the patient outside the machine itself may be treated by autoclaving, low-temperature steam, pasteurization, ethylene oxide, formaldehyde vapour, or chemical antimicrobials either as liquids or aerosols. The machine itself presents difficulties. With the exception of autoclaving all the methods just listed have been used. None are convenient, some are not very effective, and some may be dangerous if not carefully controlled. The various options have been reviewed by M. K. Sykes, ${ }^{2}$ who considers that the ideal solution is the use of detachable circuits (either heat-treatable or disposable) independent of the machine itself, which will thus not need internal decontamination. Such equipment is now becoming available, but it will be some time before it replaces that at present in use.

In 1963 the Williams filter was introduced. ${ }^{3}$ It could be used between the patient and the ventilator to protect the latter from contamination, but trapped moisture tended to increase the resistance to the flow of gas and to allow contaminating organisms to grow through. For this reason it was not very widely adopted. This filter was later modified by providing it with a heater to prevent condensation. ${ }^{4}$ Recently A. Holdcroft and her colleagues at Hammersmith have described the microbiological performance and successful use of another type of heated filter. 5 Yet another alternative is to siliconize the filter and make it water-repellent so that it does not need to be heated. Tests on this device are now reported by Drs. N. J. Mitchell and D. R. Gamble in this issue of the B.M.F. There are thus now available filters of at least two types which have been found satisfactory in practice with various sorts of ventilator. The use of such filters would largely eliminate the need to disinfect ventilators, leaving the tubing to be disinfected, preferably by heat, and the humidifier to be kept free of contamination by being run hot or filled with an antimicrobial solution. The Hammersmith paper was entitled, "Why Disinfect Ventilators?" and it would be useful if anaesthetists would ask themselves this question. If the need can be clearly defined they would save themselves and their microbiological colleagues much trouble and anxiety. If there should be a few situations in which disinfection is considered necessary, the formaldehyde method of M. K. Sykes 6 is comparatively easy to carry out, has been in routine use for nearly 10 years, and has recently been reevaluated and shown to be effective. ${ }^{7}$

To what extent are heated and siliconized filters proving successful and with what types of ventilators? The manufacturers are probably the people best able to collect such information, and they would be giving a valuable service to anaesthetists, and indeed to microbiologists, if they would do so and make their results available. An important question remains: How much infection occurring in patients on ventilators is due to the ventilator and how much to other causes? If the ventilator can be effectively exonerated by fitting it with filters the way is open for the matter to be studied epidemiologically by anaesthetists and microbiologists working together. This should prove to be of scientific interest and in the long run helpful to these patients.

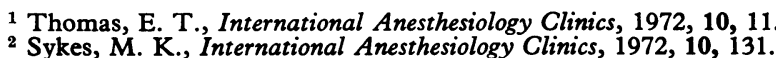

3 Bishop, C., Roper, W. A. G., and Williams, S. R., British fournal of Anaesthesia, 1963, 35, 32.

4 Pyle, P., Darlow, M., and Firman, J. E., 1969, Lancet, 1, 136.

5 Holdcroft, A., Lumley, J., and Gaya, H., 1973, Lancet, 1, 240.

- Sykes, M. K., British Medical fournal, 1964, 1, 561.

Benn, R. A. V., Dutton, A. A. C., and Tully, M., 1972, Anaesthesia, 27, 265 .

\section{Lymphocyte-depletion Hodgkin's Disease}

Even in the days before it was generally agreed that Hodgkin's disease was a true neoplasm it was observed that cases in which the lesions consisted largely of lymphocytes carried a good prognosis and those in which lymphocytes were few progressed rapidly despite treatment. H. Jackson and F. Parker, from Boston, Massachusetts, writing in 1944 divided the disease into three types: Hodgkin's paragranuloma, in which lymphocytes were the predominant cells; Hodgkin's granuloma, in which there were more ReedSternberg cells and fewer lymphocytes; and Hodgkin's sarcoma, with few lymphocytes and many reticulum cells and Reed-Sternberg cells. ${ }^{1}$ After following up cases of each type these authors concluded that Hodgkin's paragranuloma was a comparatively benign condition, Hodgkin's granuloma was usually fatal in a few years, and Hodgkin's sarcoma was rapidly fatal. ${ }^{2}$

Lately there has been a great increase in knowledge and understanding of the lymphocyte's role in immunity to 